\title{
ANODIC REACTIONS OF MOLTEN NITRATES ON GRAPHITE*
}

\author{
A. J. Arvia and W. E. Triaca \\ Instituto Superior de Investigaciones, Facultad de Quimica y Farmacia, Universidad \\ Nacional de La Plata, La Plata, Argentina
}

This is a preliminary report of the results obtained in the study of the anodic reaction occurring during the electrolysis of molten nitrates employing graphite electrodes in the temperature range from 220 to $470^{\circ} \mathrm{C}$.

As with platinum electrodes in the same melt, ${ }^{1}$ different anodic reactions can be distinguished in different temperature ranges. At least two ranges can be fixed, from 220 up to $300^{\circ} \mathrm{C}$ and from 370 up to $470^{\circ} \mathrm{C}$ or thereabouts.

In the lower temperature range the stoichiometric reaction occurring on the graphite anode is

$$
2 \mathrm{NO}_{3}{ }^{-}+\mathrm{C}=\mathrm{CO}_{2}+2 \mathrm{NO}_{2}+2 \mathrm{e}
$$

The graphite anode surface changes during the course of the reaction.

After a few minutes of the interruption of the current, a stable residual cell is established where the graphite electrode is positive with respect to the nitrate electrode ${ }^{2.3}$ used as a reference electrode. The emf of the residual cell is $0.300 \mathrm{~V}$ at $238^{\circ} \mathrm{C}$ and decreases with temperature (temperature coefficient $=-2.0 \times 10^{-3} \mathrm{~V} /{ }^{\circ} \mathrm{C}$ ).

Current/voltage curves were also obtained. The data fitted a Tafel line having a slope of $2 R T / F$ in the region of current density from 0.5 to $200 \mathrm{~mA} / \mathrm{cm}^{2}$. The apparent current density at zero overvoltage is $1 \times 10^{-4} \mathrm{~A} / \mathrm{cm}^{2}$. (Current densities are referred to apparent anode area.)

The decay of anodic overpotential is logarithmic with time (for times larger than $10 \mathrm{msec}$, depending on current density of previous electrolysis). The slopes of straight lines obtained under different conditions are in absolute terms $2 R T / F$. The analysis of the decay of the anodic overpotential also indicates that a high pseudo-capacitance is involved in the electrochemical reaction. Its value goes from 8000 to $3000 \mu F / \mathrm{cm}^{2}$ when the electrode potential increases.

The simplest explanation of these experimental results can be given in terms of a scheme of consecutive reactions where the discharge of nitrate ions on a graphite surface, having a large degree of oxidation, is the rate-determining step.

In the higher temperature region the products formed in the anode are carbon dioxide, nitrogen dioxide, nitric oxide and nitrous oxide. The ratio of nitrogen dioxide to carbon dioxide is lower than the 2 indicated by reaction (1), due to chemical reaction of the products formed in the electrode process with the graphite.

After the interruption of the current, a stable residual cell is also formed in this case, but now the graphite electrode is negative against a platinum electrode dipped in the melt and saturated with oxygen at $1 \mathrm{~atm}$. The emf of the residual cell is $0.272 \mathrm{~V}$ at $470^{\circ} \mathrm{C}$.

\footnotetext{
* Manuscript received 2 February 1965.
} 
In this range of temperature current/voltage curves indicate the existence of a polarization of a complex nature: no single Tafel line was obtained, nor could clear and definite results be obtained so far from the analysis of decay curves.

Although results at high temperature are in general less reproducible than those obtained at low temperature, nevertheless data seems to indicate that the largest part of the measured overpotential is probably due to the existence of a concentration type of overpotential caused by the different degree of oxidation of the graphite surface. However, it is likely that some activation overpotential term is also involved.

A detailed description and discussion of the results will be published in the near future.

Acknowledgement-This work is supported with funds of the Consejo Nacional de Investigaciones Cientificas y Técnicas de la República Argentina. W. E. T. thanks the Consejo for the fellowship granted.

\section{REFERENCES}

1. W. E. Triaca and A. J. Arvia, Electrochim. Acta 9, 1055 (1964); 10, 409 (1965).

2. J. A. A. KetelaAr and A. Dammers-De Klerk, Rec. Trav. Chim. Pays-Bas 83, 322 (1964).

3. W. E. TriacA and A. J. ArviA, Electrochim. Acta. 9, 919 (1964). 